\title{
Thermodynamically study of phase formation of Ni-Ti-Si nanocomposites produced by self-propagating high- temperature synthesis method
}

\author{
Hossein Aghajani ${ }^{\text {a,* }}$, Arvin Taghizadeh Tabrizi ${ }^{\text {a,b }}$, Salva Arabpour Javadi ${ }^{\text {c }}$ \\ Mohammad Ehsan Taghizadeh Tabrizi ${ }^{d}$, Aytak Homayouni ${ }^{d}$, Sahand Behrangi ${ }^{e}$ \\ ${ }^{a}$ School of Metallurgy \& Materials Engineering, Iran University of Science and Technology, Narmak, Tehran, Iran \\ ${ }^{b}$ Nanotechnology Research \& Application Center, Sabanci University, Tuzla 34956, Istanbul, Turkey \\ ${ }^{c}$ Materials Engineering Department, University of Tabriz, Tabriz, Iran \\ ${ }^{d}$ Faculty of Mechanical Engineering, University of Tabriz, Tabriz, Iran \\ ${ }^{e}$ Department of Physical Electronics, Masaryk University, Brno, Czech
}

\section{A B S T R A C T}

Understanding the phase formation mechanisms in self-propagating high-temperature synthesis from the thermodynamical aspect of view is important. In this study, the phase formation of the ternary system of nickel-titanium-silicon was studied by using the HSC software V6.0, and phase formation is predicted by calculating the adiabatic temperature of exothermic reaction between reagents. Then, by using X-ray diffractometer analysis, the results of the simulation were evaluated by experimental achievements. Results showed a good correlation between thermodynamical calculation and prediction with experimental. It could be concluded that the equilibrium mechanism is the dominant mechanism in phase formation in the SHS synthesis method. NiTiSi solid solution phase is obtained from the reaction between $\mathrm{Ti}_{5} \mathrm{Si}_{3}$ and $\mathrm{Ni}_{2} \mathrm{Si}$ and $\mathrm{Ni}$.

C 2021 The Authors. Published by Synsint Research Group.
KEYWORDS

\author{
Thermodynamic \\ Adiabatic temperature \\ Self-propagating high-temperature \\ synthesis
}

Phase formation

\section{Introduction}

Improvement of the engineering materials is the essential issue to help researchers, scientists, and engineers to fulfill the needs of human beings [1]. For approaching this aim, materials engineering has two important tasks. One is to improve the required properties of the selected materials and the second is to the synthesis of newly developed materials. To meet these tasks, synthesizing different composites and nanocomposites attracts much attention among materials and manufacturing engineering. Different types of composites including metal-based, ceramic-based, and polymer-based are introduced. Different synthesizing methods have been used to obtain specific composites like friction stir processing [2], casting [3], hot isostatic pressing [4], powder metallurgy [5], spark plasma sintering [6], In situ synthesis, 3D printing [7] and self-propagating high-temperature synthesis (SHS) methods [8].

Among these methods, self-propagating high-temperature synthesis (SHS) is a method based on the initiation of exothermic reaction between initial ingredients as a powder in an adiabatic container [9]. This adiabatic container helps to keep the produced heat from a chemical reaction and causes the required energy to continue the reaction and achieving the final considered composition [10,11]. Besides, due to the simplicity and lower costs, and lower time in this method, it attracts much attention and diverse studies had been conducted on copper-based nanocomposites [12-14], titanium-based

\footnotetext{
* Corresponding author. E-mail address: haghajani@iust.ac.ir (H. Aghajani)

Received 18 August 2021; Received in revised form 5 November 2021; Accepted 5 November 2021.

Peer review under responsibility of Synsint Research Group. This is an open access article under the CC BY license (https://creativecommons.org/licenses/by/4.0/). https://doi.org/10.53063/synsint.2021.1443
} 
composites [15], aluminum-based composites [16] and even synthesizing of high entropy alloys $[17,18]$. Also, this method had a high potential to use in the mass production of considered composites.

This route is based on exothermic reactions and, by occurring the selfsustained reaction between the elemental powders; well-desired products could be obtained. Due to this reason, a high amount of exothermic heat of the reactions between initial powders, the behavior of prepared powders during the SHS process completely depends on the thermodynamically and kinetic condition of the experiments. The ratio of the mixed samples, the value of their Gibbs energy of the probable reactions, particle-sized of the initial powders, etc. influence the properties of the obtained composite and its phase formation. As it is mentioned before, the self-propagating reaction is occurred in an adiabatic container that is filled with inert gas like argon. The green sample is placed on the sample holder and initiating reaction is triggered by using electric power which is supplied by the transformer to overcome the activation energy. In table 1, a list of the newly developed composites by the SHS method is listed. It is shown that different compositions were studied and phase formation of the produced nanocomposites has been investigated experimentally.

Table 1. Newly developed composites by SHS method.

\begin{tabular}{|c|c|c|c|c|}
\hline No. & Composite & $\begin{array}{c}\text { Used } \\
\text { Powders }\end{array}$ & Feature Studied & Reference \\
\hline 1 & $\mathrm{Cu}-\mathrm{TiO}_{2}$ & $\mathrm{CuO}, \mathrm{Ti}$ & Phase formation & {$[12,13]$} \\
\hline 2 & Cu-Ti-B & $\mathrm{Cu}, \mathrm{Ti}, \mathrm{B}$ & Corrosion behavior & [14] \\
\hline 3 & Al-Ti-B & $\mathrm{Al}, \mathrm{Ti}, \mathrm{B}$ & Phase formation & [19] \\
\hline 4 & $\begin{array}{c}\text { High Entropy } \\
\text { Alloy of } \\
\text { NiTiSi }\end{array}$ & $\mathrm{Ni}, \mathrm{Ti}, \mathrm{Si}$ & $\begin{array}{l}\text { Corrosion behavior } \\
\text { Phase formation }\end{array}$ & [20] \\
\hline 5 & $\begin{array}{c}\mathrm{Al}-\mathrm{TiO}_{2}- \\
\mathrm{B}_{2} \mathrm{O}_{3}\end{array}$ & $\begin{array}{c}\mathrm{Al}, \mathrm{TiO}_{2}, \\
\mathrm{~B}_{2} \mathrm{O}_{3}\end{array}$ & Wear resistance & {$[21]$} \\
\hline 6 & $\mathrm{Ni} / \mathrm{NiO}$ & $\begin{array}{c}\mathrm{Ni}\left(\mathrm{NiO}_{3}\right)_{2} \\
\mathrm{NH}_{4} \mathrm{OH}\end{array}$ & Optical properties & {$[22]$} \\
\hline 7 & $\begin{array}{c}\mathrm{Al}-\mathrm{Fe}_{2} \mathrm{O}_{3-} \\
\mathrm{Cr}_{2} \mathrm{O}_{3}\end{array}$ & $\begin{array}{c}\mathrm{Al}, \mathrm{Fe}_{2} \mathrm{O}_{3} \\
\mathrm{Cr}_{2} \mathrm{O}_{3}\end{array}$ & Microhardness & {$[23]$} \\
\hline 8 & $\begin{array}{c}\mathrm{Al}-\mathrm{Fe}_{2} \mathrm{O}_{3} / \mathrm{Al}- \\
\mathrm{Cr}_{2} \mathrm{O}_{3} \\
\text { Coating }\end{array}$ & $\begin{array}{c}\mathrm{Al}, \mathrm{Fe}_{2} \mathrm{O}_{3} \\
\mathrm{Cr}_{2} \mathrm{O}_{3}, \mathrm{SiO}_{2}\end{array}$ & Phase formation & [24] \\
\hline 9 & $\begin{array}{l}\mathrm{TiB}_{2} / \mathrm{Al}-\mathrm{Zn}- \\
\mathrm{Mg}-\mathrm{Cu}-\mathrm{Zr}\end{array}$ & $\begin{array}{c}\mathrm{Al}, \mathrm{Ti} \\
\mathrm{H}_{3} \mathrm{BO}_{3}, \mathrm{TiO} 2\end{array}$ & Phase formation & {$[25]$} \\
\hline 10 & $\mathrm{Al}_{2} \mathrm{O}_{3}-\mathrm{ZrB}_{2}$ & $\begin{array}{c}\mathrm{ZrO}_{2}, \mathrm{Al}, \\
\mathrm{B}_{2} \mathrm{O}_{3}\end{array}$ & Phase formation & {$[26]$} \\
\hline 11 & $\begin{array}{c}\mathrm{Al}_{2} \mathrm{O}_{3}-\mathrm{TiB}_{2-} \\
\text { TiC/Al } \\
\text { Coating }\end{array}$ & $\begin{array}{c}\mathrm{Al}, \mathrm{TiO}_{2}, \\
\mathrm{~B} 4 \mathrm{C}\end{array}$ & Phase formation & [27] \\
\hline 12 & TiB-Ti & $\mathrm{Ti}, \mathrm{B}$ & Electrical properties & {$[28]$} \\
\hline 13 & $\mathrm{Nb}_{5} \mathrm{Si}_{3}$ & $\mathrm{Nb}, \mathrm{Si}$ & $\begin{array}{c}\text { Phase formation \& } \\
\text { mechanical } \\
\text { properties }\end{array}$ & [29] \\
\hline 14 & $\begin{array}{l}\text { NiAl-TiC- } \\
\mathrm{TiB}_{2}\end{array}$ & $\begin{array}{l}\mathrm{Ni}, \mathrm{Al}, \mathrm{Ti}, \\
\mathrm{B}_{4} \mathrm{C}\end{array}$ & $\begin{array}{c}\text { Thermal \& } \\
\text { corrosion properties }\end{array}$ & {$[30]$} \\
\hline 15 & $\mathrm{Al}^{-\mathrm{TiB}_{2}}$ & $\mathrm{Ti}, \mathrm{Al}, \mathrm{B}_{2} \mathrm{O}_{3}$ & Phase formation & {$[31]$} \\
\hline
\end{tabular}

Obtained phases in the final products in this method, play an important role in determining the desired properties. The aim is to achieve a solid solution but the ratio of raw materials is a critical parameter. Therefore, prediction of phase formation of nanocomposites synthesized by the SHS method could be possible by determining the phase formation mechanisms [32]. SHS synthesis consists of two stages of combustion and structure formation. There are two different mechanisms including equilibrium and nonequilibrium. Different studies have been done before on the possibility of the synthesizing of different composites the SHS method $[31,33]$ by there is a rare study to investigate the phase formation in this method. Therefore, and in this investigation, the ternary system of Ni-Ti-Si was considered and phase formation of this system was studied from the thermodynamic aspect of view and calculation of Gibbs free energy values by using HSC software V6.0. The results are compared by experimental phase formation of $\mathrm{Ni}-\mathrm{Ti}-\mathrm{Si}$ nanocomposites synthesized by the SHS route.

\section{Experimental}

High purity of nickel, titanium and silicon micro powders were used and Ni-Ti-Si nanocomposites were synthesized by SHS route based on our previous work [20]. Briefly, initial powders nickel, titanium, and silicon were mixed mechanically at the 1:1:1 ratio at $300 \mathrm{rpm}$ for 72 hours at an argon atmosphere. Also, PVA was added to the mixed powders and cold pressed at $30 \mathrm{MPa}$ in dimensions of $30 \mathrm{~mm}$ in diameter and $20 \mathrm{~mm}$ in height. The green compact was placed at the SHS chamber and the container was filled by argon atmosphere. The SHS process was initiated by tungsten electrode and reaction was taken place in whole sample. The schematic of the synthesizing is presented in Fig. 1. It is worth mentioning that three samples were synthesized to show the repeatability of the achievements. For the detection of the formation of phases, X-ray diffractometry (XRD) was used which was equipped with a $\mathrm{Cu} \mathrm{Ka} \mathrm{X}$-ray lamp with a wavelength of $1.54^{\circ} \mathrm{A}$. To detect the all-possible phases scan rate was reduced to 1 degree/min and the scan step was reduced to $0.01 \mathrm{degree} / \mathrm{min}$. Microstructure analysis was carried out by using field emission scanning electron microscopy (FE-SEM-VEGA TESCAN). Also, to study the homogeneity and uniformity of phase formations in the whole sample, two distinct areas (upper and bottom) were analyzed by FE-SEM.

\section{Results and discussion}

\subsection{Calculation of adiabatic temperature}

In the case of the SHS process, thermodynamics is used to calculate the adiabatic temperature of the reactions $\left(\mathrm{T}_{\mathrm{ad}}\right)$ and equilibrium possible products. As mentioned before, the SHS method is based on exothermic reactions as shown in Eq. 1.

$\mathrm{A}+\mathrm{B}=\mathrm{C}+\mathrm{Q}$

The standard enthalpy of formation of components in the reaction should be determined, like $\Delta \mathrm{H}^{\circ}(\mathrm{A}), \Delta \mathrm{H}^{\circ}(\mathrm{B})$, and $\Delta \mathrm{H}^{\circ}(\mathrm{C})$, where is zero for elements. As shown the $\mathrm{Q}$ produced within the reaction, in an adiabatic container, which could be calculated by the difference of the standard enthalpy of the components. Under the adiabatic condition, the produced heat is used to increase the temperature of products to adiabatic temperature which could be calculated through Eq. 2:

$\mathrm{Q}=\int_{\mathrm{T}_{0}}^{\mathrm{T}_{\mathrm{ad}}} \mathrm{c}(\mathrm{T}) \mathrm{dt}$ 
Where $c(T)$ is specific heat of the products and it is the function of temperature as Eq. 3:

$\mathrm{c}(\mathrm{T})=\mathrm{A}+\mathrm{BT}+\mathrm{CT}^{2}$

With combining Eq. 1 and 2, adiabatic temperature could be calculated through Eq. 4:

$\frac{\mathrm{C}}{3} \mathrm{~T}_{\mathrm{ad}}^{3}+\frac{\mathrm{B}}{2} \mathrm{~T}_{\mathrm{ad}}^{2}+\mathrm{AT}_{\mathrm{ad}}-\left[\mathrm{Q}+\frac{\mathrm{C}}{3} \mathrm{~T}_{0}^{3}+\frac{\mathrm{B}}{2} \mathrm{~T}_{0}^{2}+\mathrm{AT}_{0}\right]=0$

Where $T_{0}$ could be assumed equal to room temperature, $298 \mathrm{~K}$. Usually the produced heat, $\mathrm{Q}$, is too much which increases the temperature remarkably where it passes phase transitions temperature. In this case, Eq. 1 should be rewritten as below regarding latent enthalpy of transition and the mole fraction of the phase obtained in the product:

$\mathrm{Q}-\sum_{\mathrm{i}=1}^{\mathrm{n}}\left(\Delta \mathrm{H}_{\mathrm{ph}}^{\mathrm{i}}-\mathrm{X}_{\mathrm{ph}} \Delta \mathrm{H}_{\mathrm{ph}}\right)=\int_{\mathrm{T}_{0}}^{\mathrm{T}_{\mathrm{ad}}} \mathrm{c}(\mathrm{T}) \mathrm{dt}$

This increase in temperature could lead to the combustion wave and complete the synthesizing process. To predict the final products and due to their complexity, the calculation must be done by special software like HSC V6.0 software, Thermo-Calc. or any other thermodynamical software.

\subsection{Phase prediction by HSC software V6.0}

Regarding the initial ingredients of the synthesized nanocomposites including titanium, nickel, and silicon, the ternary phase diagram of NiTi-Si and binary phases of Ni-Ti, Ni-Si and Ti-Si must be studied to predict the final phases and mechanism of solid solution formation. It is well known that thermodynamical study is essential to study the chemical reactions and it is the first condition that shows the possibility of the reaction occurrence by determining the value of Gibbs free energy. The phase relationship in a system with more than one component, e.g. two components, could be presented on an isobaric phase diagram using temperature and chemical composition which are known as phase diagrams. Therefore, for approaching this purpose, the binary possible solid solutions phases were detected from the phase diagram of these systems, and possible chemical reactions for obtaining the products were determined and studied. After that, the value of the formation Gibbs free energy of detected phases was calculated by HSC software V6.0. By comparing the achieved values, the steps of solid solutions were revealed. The binary phase diagram of $\mathrm{Ni}-\mathrm{Ti}, \mathrm{Ni}-\mathrm{Si}$, and Ti-Si systems is presented in Fig. 2.

As it is shown in Fig. 2a, NiTi, $\mathrm{NiTi}_{2}$, and $\mathrm{Ni}_{3} \mathrm{Ti}$ are three stable phases that could be formed within the SHS process. The value of the activity of the component depends on the composition and the nature of the components of the solution and temperature and it necessarily influences the equilibrium state of any chemical reaction system in which the determining component is involved. Therefore, the Gibbs free energy of formation of these was calculated according to Eq. 6 as below:

$\Delta \mathrm{G}_{\mathrm{Ni}_{\mathrm{a}} \mathrm{Ti}_{\mathrm{b}}}^{\mathrm{M}}=\mathrm{X}_{\mathrm{Ni}} \mathrm{G}_{\mathrm{Ni}}^{\mathrm{M}}+\mathrm{X}_{\mathrm{Ti}} \mathrm{G}_{\mathrm{Ti}}^{\mathrm{M}}=\mathrm{RT}\left(\mathrm{X}_{\mathrm{Ni}} \mathrm{Lna}_{\mathrm{Ni}}+\mathrm{X}_{\mathrm{Ti}} \mathrm{Lna}_{\mathrm{Ti}}\right)$

Dissolving the pure component in a condensed solution that is in contact with a liquid phase causes a decrease in the activity of that component. Since the temporary liquid phase was formed within the SHS process, the molar fraction of the liquid phase components have lower values. As phase equilibrium is maintained between the liquid phase and the condensed solution, the partial molar Gibbs free energy of component in the solution is $\operatorname{RTLn}\left(\mathrm{a}_{\mathrm{i}}\right)$ lower than the molar Gibbs free energy of pure condensed component at the temperature $\mathrm{T}$. It is necessary to mention that for simplicity of the calculations, ideal solution conditions were considered $(\mathrm{a}=\mathrm{X})$.

According to Eq. 5, and HSC software V6.0, the Gibbs free energy for $\mathrm{NiTi}, \mathrm{NiTi}_{2}$, and $\mathrm{Ni}_{3} \mathrm{Ti}$ was calculated and equals $-53.18,-65.07$, and $152.73 \mathrm{~kJ} / \mathrm{mol}$ respectively. This indicates that the formation of $\mathrm{Ni}_{3} \mathrm{Ti}$ is more probable due to the more negative value of free formation Gibbs energy. The Gibbs free energy of these three phases is shown in Fig. 3. Also, it could be observed that with increasing the temperature, the value of the Gibbs free energy is decreased and reached more negative values which leads the chemical reaction to produce more product and complete the reaction. Also, the adiabatic container of the SHS process helps to increase the temperature and helps to complete the chemical reactions to form determined phases. It is worth mentioning that the decrease which is observed in the Gibbs free energy curve of the $\mathrm{Ni}_{3} \mathrm{Ti}$ phase is remarkable and a decrease in the amount of Gibbs free energy has happened with a severe slope. This indicates that by increasing the temperature and decreasing the values of Gibbs free energy, the $\mathrm{Ni}_{3} \mathrm{Ti}$ phase is a more probable phase to form in the $\mathrm{Ni}-\mathrm{Ti}$ system thermodynamically.

According to the phase diagram of system Ni-Si, presented in Fig. 2b, three different stable phases could be detected including $\mathrm{Ni}_{2} \mathrm{Si}, \mathrm{NiSi}$, and $\mathrm{NiSi}_{2}$. The diagram of the Gibbs free energy them is presented in Fig. 4. The calculated Gibbs free energy equals $-131.47,-80.6$, and $86.11 \mathrm{~kJ} / \mathrm{mol}$ for phases $\mathrm{Ni}_{2} \mathrm{Si}, \mathrm{NiSi}$, and $\mathrm{NiSi}_{2}$ respectively which implies that the $\mathrm{Ni}_{2} \mathrm{Si}$ phase is the most convenient phase to obtain thermodynamically. The same phenomenon of the Ni-Ti system is observed here, I system Ni-Si. The increase in the temperature causes the decrease in the Gibbs free energy values of all three-phase, but here and in this system, all three phases face an almost equal decrease with the same slope.

According to the phase diagram of Ti-Si, presented in Fig. 2c, three different stable phases could be detected including $\mathrm{Ti}_{5} \mathrm{Si}_{3}, \mathrm{TiSi}$, and

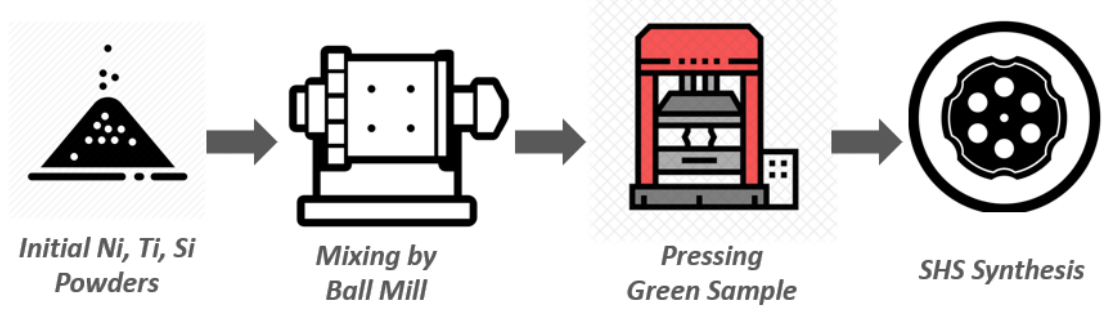

Fig. 1. Schematic of SHS synthesized nanocomposite preparation. 
a)

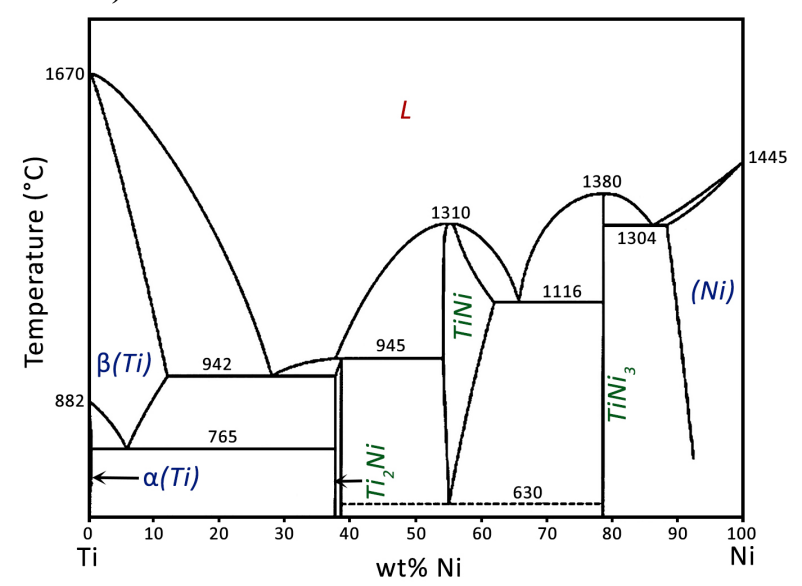

b)

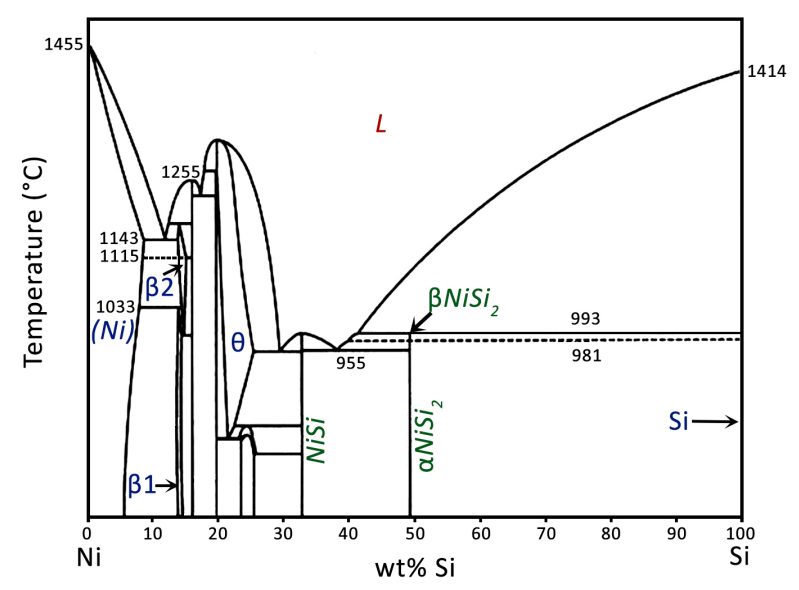

c)

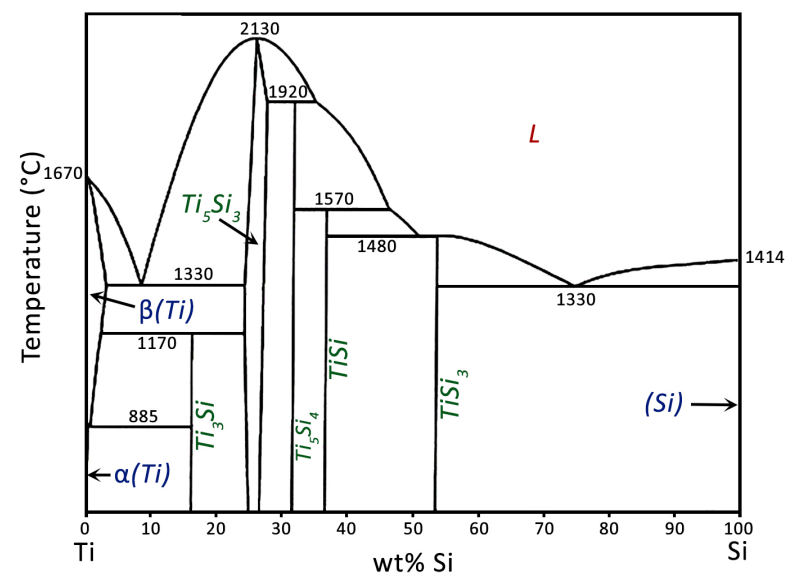

Fig. 2. Phase diagram of a) Ni-Ti, b) Ni-Si, and c) Ti-Si [34].

$\mathrm{TiSi}_{2}$. The diagram of the Gibbs free energy of them is presented in Fig. 5, where it is shown that the sample $\mathrm{Ti}_{5} \mathrm{Si}_{3}$ has the most negative formation Gibbs free energy equals $-589.26 \mathrm{~J} / \mathrm{mol}$. This value is the most negative calculated value and this phase is determined as the first phase to form in the ternary system.

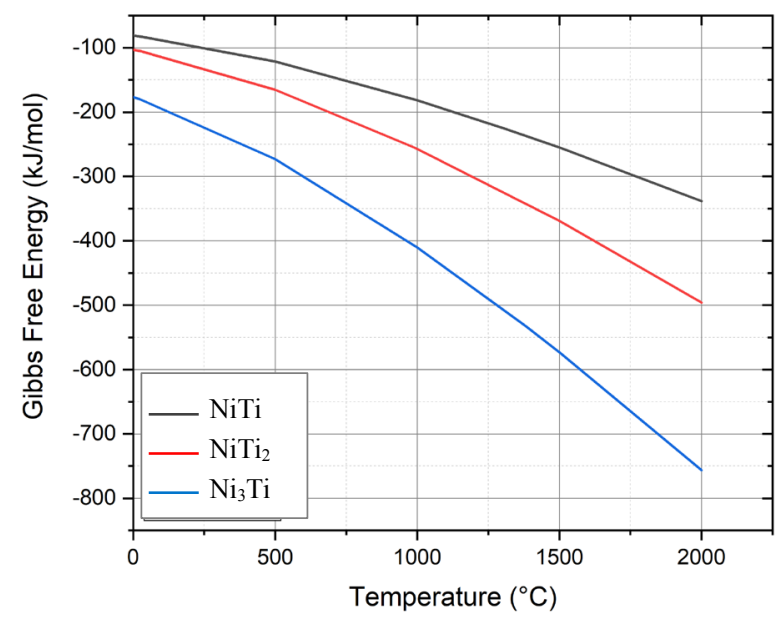

Fig. 3. Gibbs free energy of Ni-Ti phases.

With determining the first binary solution, the $\mathrm{Ti}_{5} \mathrm{Si}_{3}$ phase is a determined phase to form according to the Gibbs free energy. To form a ternary solid solution phase, nickel must be involved in a chemical reaction. Regarding the phase relationship plot of $\mathrm{Ni}$-involved phases at a determined temperature which is presented in Fig. 6, below chemical reaction could be considered to form a solid solution. Fig. 6 presents the phase equilibrium of Ni-involved phases. Since the $\mathrm{Ti}_{5} \mathrm{Si}_{3}$ phase is the first phase in the ternary system of $\mathrm{Ni}-\mathrm{Ti}-\mathrm{Si}$, and $\mathrm{Ni}$ has remained. Therefore, as it is shown in chemical reaction 1 , the $\mathrm{Ti}_{5} \mathrm{Si}_{3}$ phase reacts with nickel-involved phases. Also, due to consuming less Si powder for the formation of the $\mathrm{Ti}_{5} \mathrm{Si}_{3}$ phase at the first step, Si powders have probably remained and phases in $\mathrm{Ni}-\mathrm{Si}$ systems are more probable to form. According to the Gibbs free energies of phases in the $\mathrm{Ni}-\mathrm{Si}$ binary system, which mentioned before, the $\mathrm{Ni}_{2} \mathrm{Si}$ phase is more likely to form. According to the Eq. 1, extra remained nickel could participate in the reaction to form a ternary solid solution as below:

$\mathrm{Ni}_{(\mathrm{s})}+\mathrm{Ti}_{5} \mathrm{Si}_{3(\mathrm{~s})}+2 \mathrm{Ni}_{2} \mathrm{Si}_{(\mathrm{s})} \rightarrow 5 \mathrm{NiTiSi}$

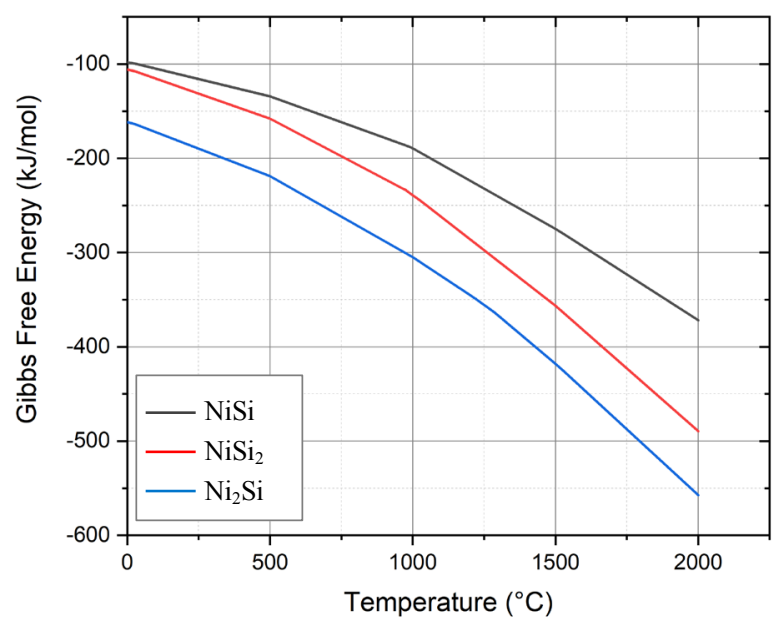

Fig. 4. Gibbs free energy of Ni-Si phases. 


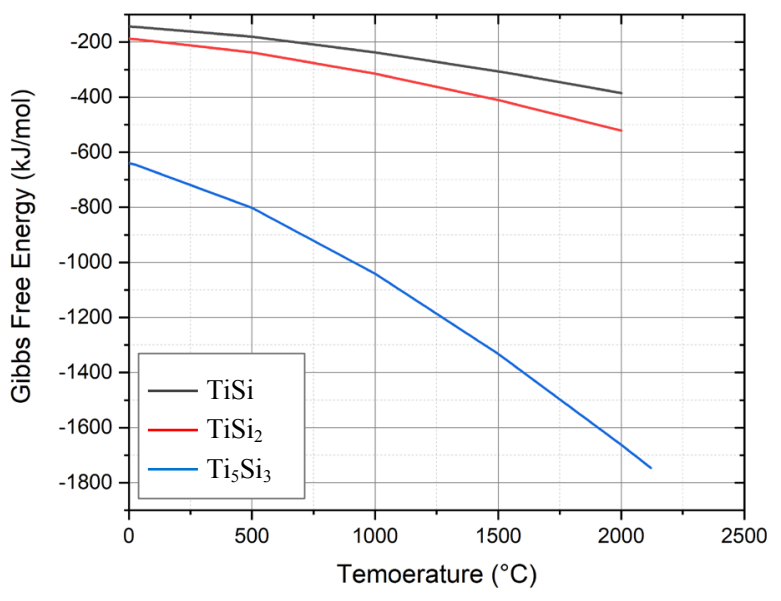

Fig. 5. Gibbs free energy of Ti-Si phases.

\subsection{Phase detection}

For validifying the predicted results by thermodynamical calculations, three samples were synthesized by SHS method and phase formation of them was studied through X-ray diffractometer. The XRD patterns of the obtained nanocomposites are exhibited in Fig. 7, and it is shown the successful formation of the ternary solid solution of the determined NiTiSi phase with an orthorhombic structure. The obtained phase confirms the proposed thermodynamical phase formation sequence and mechanism in the prior section, 3.2. Also, it is shown that no oxide phase was formed within the synthesized process. Also, there is another phase is detected in the XRD pattern, $\mathrm{Ni}_{49} \mathrm{Si}_{37} \mathrm{Ti}_{14}$. The formation of this phase may be influenced by other kinetic parameters which need more studies to be revealed. But the height of peaks obtained in each sample differs. Sample 3 (S3) exhibits more sharp peaks which implies the complete formation of ternary solid solution. The observed background in the presented XRD pattern implies the formation of an amorphous phase too within the SHS process, which is due to the rapid cooling rate of the synthesized sample. According to the XRD pattern of sample 2 (S2), more amorphous phase was formed within the synthesizing process and the background pattern fluctuation is lower in XRD patterns of S1 and S3. The crystallite size was calculated using the Scherrer relation which equals $120 \mathrm{~nm}$ for S3:

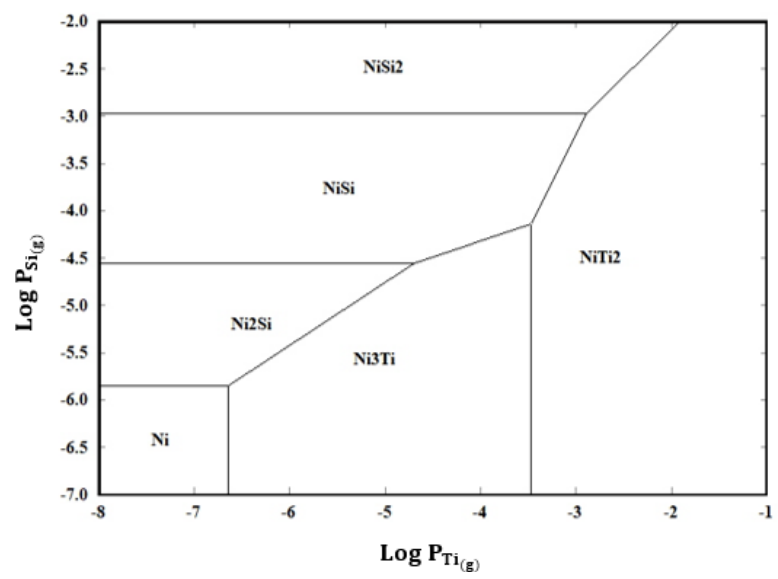

Fig. 6. Phase relationships involved Ni-phase.
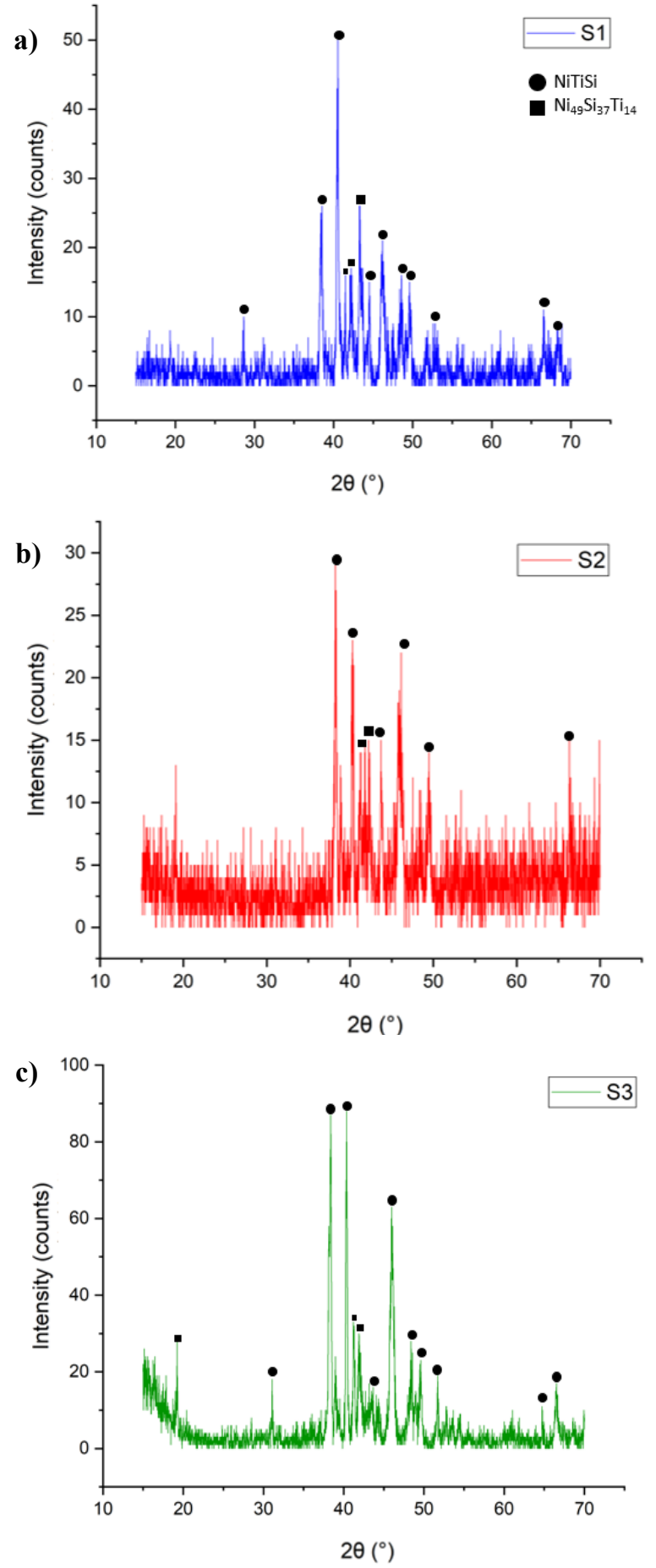

Fig. 7. XRD pattern of synthesized sample and solid solution formation of NiTiSi a) S1, b) S2 and c) S3.

$\mathrm{L}=\frac{\mathrm{k} \lambda}{\mathrm{B} \cos \theta}$

where $\mathrm{L}$ is the crystallite size, $\mathrm{B}$ is the peak broadening at the half of the height, $\theta$ is the diffracted angle, $\lambda$ is the wavelength of the copper $\mathrm{X}$-ray lamp and it equals to 1.5406 Angstrom. 

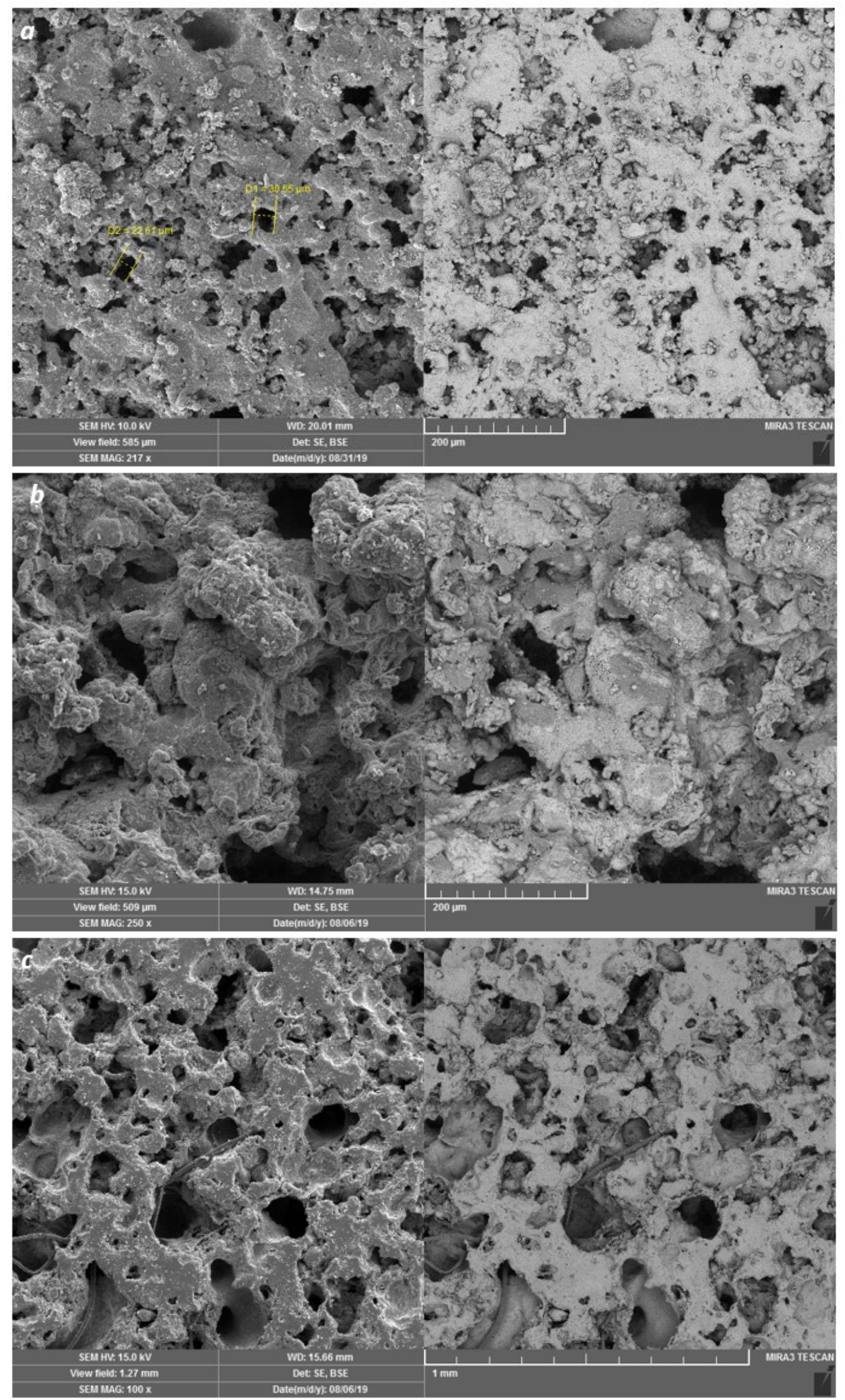

Fig. 8. FE-SEM images of morphology of achieved nanocomposite a) S1, b) S2 and c) S3. 

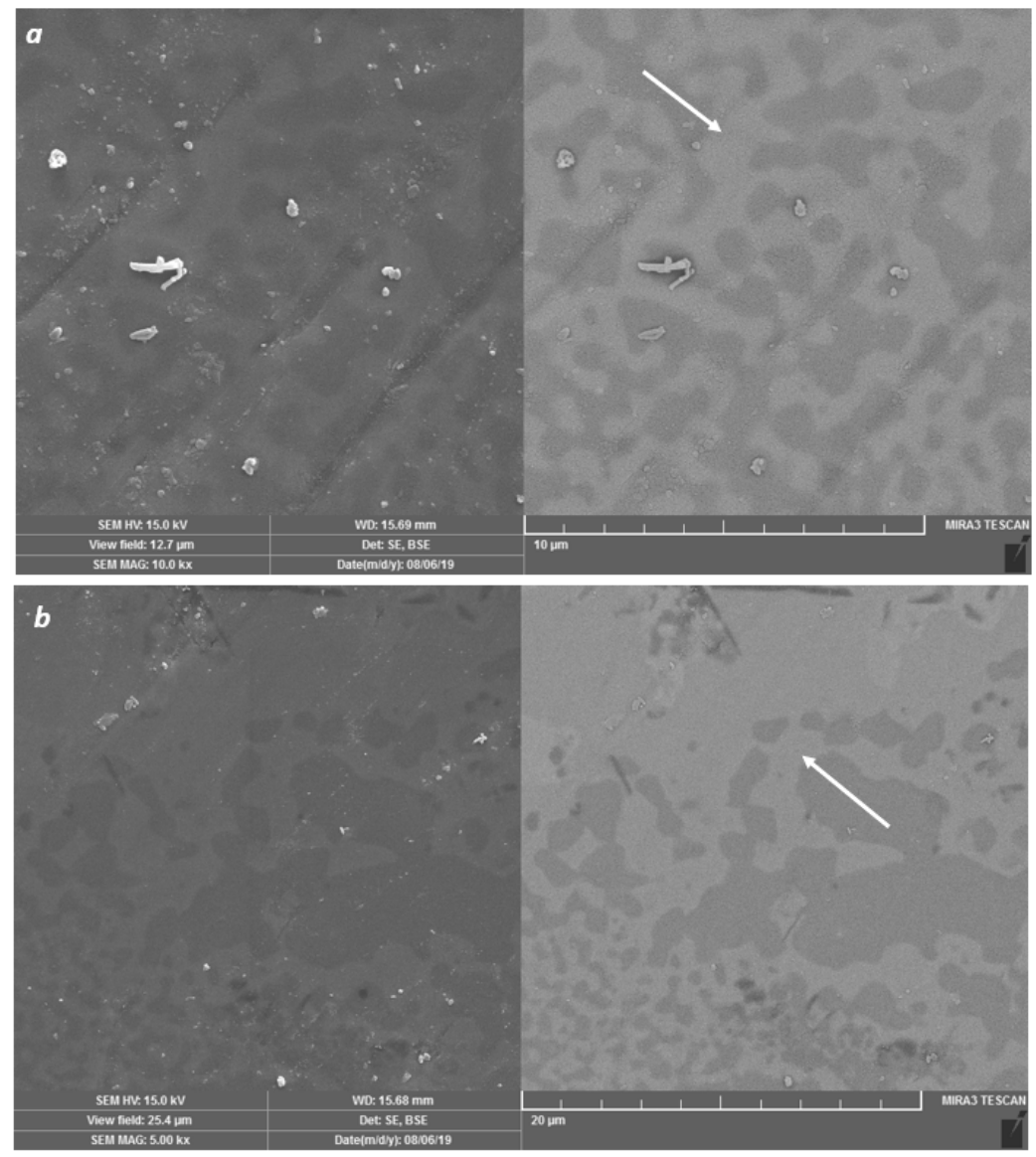

Fig. 9. Formation of solid solution a) upper area and b) bottom area of syntehszied sample.

The morphology of the synthesized sample was studied by field emission scanning electron microscopy (FE-SEM). All achieved samples were porous and their structure shows the porosities with different sizes from $25 \mathrm{~nm}$ to $70 \mathrm{~nm}$. Almost all the porosities are connected with each other and formed the open cell porous nanocomposite. The FE-SEM images of this kind of morphology are presented in Fig. 8. The uniformity and homogeneity of the obtained synthesized sample are depended on the adiabatic temperature, combustion wave. Since the combustion was initiated by electrode sparks from the surface of the sample in the SHS container, the combustion wave moved from up to down of the sample. Increasing the temperature in the adiabatic system leads to an increase in the temperature to combustion temperature to finish the synthesis process. For evaluating the homogeneity and uniformity of phase formation in synthesized samples, FE-SEM was carried out from two different sections of the sample, the upper area, and bottom area. FE-SEM images are shown in Fig. 9. It is shown that the solid solution is completely formed within the synthesizing process. Regarding the dimension of the samples and also calculated adiabatic temperature, a temporary liquid phase was achieved within the SHS synthesis process and the gravity force and capillary force due to the presence of porosities pull the liquid phase down and it is expected more solid solution was obtained in the bottom area of the samples. The FE-SEM images of Fig. 8, a for upper areas and $b$ for bottom areas confirm this acclaim and show the formation of a more solid solution at bottom areas.

\section{Conclusions}

The NiTiSi solid solution is synthesized successfully and the synthesizing and phase formation was studied by the thermodynamical aspect of view. The proposed thermodynamical mechanism of NiTiSi phase formation is valid according to the experimental results obtained from XRD and FE-SEM studied. Firstly, the formation of $\mathrm{Ti}_{5} \mathrm{Si}_{3}$ has happened and then with the addition of $\mathrm{Ni}$ and $\mathrm{Ni}_{2} \mathrm{Si}$, a ternary solid solution of NiTiSi was formed. It is shown that the gravity force and capillary force affect the uniformity and homogeneity of the achieved synthesized sample through the self-propagating high-temperature synthesis (SHS) method.

\section{References}

[1] A. T. Tabrizi and M. Azadbeh, The Effect of Transient Liquid Phase on the Joining Process of Aluminum Foam Core Sandwiches, Powder Metall. Prog. 16 (2016) 48-58. https://doi.org/10.1515/pmp2016-0005.

[2] F. Karpasand, A. Abbasi, and M. Ardestani, Effect of amount of $\mathrm{TiB} 2$ and $\mathrm{B} 4 \mathrm{C}$ particles on tribological behavior of A17075/B4C/TiB2 mono and hybrid surface composites produced by friction stir processing, Surf. Coatings Technol. 390 (2020) 125680. https://doi.org/10.1016/j.surfcoat.2020.125680.

[3] Ł.Rogal, Semi-solid processing of the $\mathrm{CoCrCuFeNi}$ high entropy alloy, Mater. Des. 119 (2017) 406-416. https://doi.org/10.1016/j.matdes.2017.01.082. 
[4] B. Biswas, Y. Purandare, A. Sugumaran, I. Khan, and P. E. Hovsepian, Effect of chamber pressure on defect generation and their influence on corrosion and tribological properties of HIPIMS deposited CrN/NbN coatings, Surf. Coatings Technol. 336 (2017) 84-91. https://doi.org/10.1016/j.surfcoat.2017.08.021.

[5] M. R. Gorji, C. Edtmaier, and S. Sanjabi, Synthesis of Ni/TiC composite coating by infiltration sintering of electrophoretic deposited layers, Mater. Des. 125 (2017) 167-179. https://doi.org/10.1016/j.matdes.2017.04.002.

[6] H. Hadraba, Z. Chlup, A. Dlouny, F. Dobes, P. Roupcova, M. Vilemova, J. Matejicek, Oxide dispersion strengthened CoCrFeNiMn high-entropy alloy, Mater. Sci. Eng. A. 689 (2017) 252-256. https://doi.org/10.1016/j.msea.2017.02.068.

[7] R. Dhandapani, P.D. Krishnan, A. Zennifer, V. Kannan, A. Manigandan, M.R. Arul, D. Jaiswal, A. Subramanian, S.G. Kumbar, S. Sethuraman, Additive manufacturing of biodegradable porous orthopaedic screw, Bioact. Mater. 5 (2020) 458-467. https://doi.org/10.1016/j.bioactmat.2020.03.009.

[8] V. V. Kurbatkina, E. I. Patsera, E. A. Levashov, and A. N. Timofeev, Self-propagating high-temperature synthesis of single-phase binary tantalum-hafnium carbide $(\mathrm{Ta}, \mathrm{Hf}) \mathrm{C}$ and its consolidation by hot pressing and spark plasma sintering, Ceram. Int. (2017). https://doi.org/10.1016/j.ceramint.2017.12.024.

[9] P. Mossino, Some aspects in self-propagating high-temperature synthesis, Ceram. Int. 30 (2004) 311-332. https://doi.org/10.1016/S0272-8842(03)00119-6.

[10] M. Rezaeezadeh, M. Shafiee Afarani, and M. Sharifitabar, WC-TiCAl2O3 composite powder preparation by self-propagating hightemperature synthesis route, Ceram. Int. 43 ( 2017). https://doi.org/10.1016/j.ceramint.2017.08.128.

[11] G. J. Feng, Z. R. Li, S. C. Feng, and Z. K. Shen, Effect of Ti-Al content on microstructure and mechanical properties of $\mathrm{Cf} / \mathrm{Al}$ and TiAl joint by laser ignited self-propagating high-temperature synthesis, Trans. Nonferrous Met. Soc. China (English Ed). 25 (2015) 1468-1477. https://doi.org/10.1016/S1003-6326(15)63747-5.

[12] N. A. Golnaz, T. T. Arvin, and H. Aghajani, Investigation on corrosion behavior of $\mathrm{Cu}-\mathrm{TiO} 2$ nanocomposite synthesized by the use of SHS method, J. Mater. Res. Technol. 8 (2019) 2216-2222. https://doi.org/10.1016/j.jmrt.2019.01.025.

[13] S. S. Javaherian, H. Aghajani, and P. Mehdizadeh, Cu-TiO2 composite as fabricated by SHS method, Int. J. Self-Propagating High-Temperature Synth. 23 (2014) 47-54. https://doi.org/10.3103/S1061386214010051.

[14] S. A. N. Mehrabani, A. T. Tabrizi, H. Aghajani, and H. Pourbagheri, "Corrosion Behavior of SHS-Produced Cu-Ti-B Composites, Int. J. Self-Propagating High-Temperature Synth. 29 (2020) 167-172. https://doi.org/10.3103/S1061386220030061.

[15] B. Y. Tay, C.W. Goh, Y.W. Gu, C.S. Lim, M.D. Yong, M.K. Ho, M.H. Myint, Porous NiTi fabricated by self-propagating hightemperature synthesis of elemental powders, J. Mater. Process. Technol. 202 (2008) 359-364. https://doi.org/10.1016/j.jmatprotec.2007.09.037.

[16] X. Liu and H. Hao, The influence of carbon content on Al-Ti-C master alloy prepared by the self-propagating high-temperature synthesis in melt method and its refining effect on AZ31 alloy, J. Alloys Compd. 623 (2015) 266-273. https://doi.org/10.1016/j.jallcom.2014.10.131.

[17] S. Qiu, N. Miao, J. Zhou, Z. Guo, and Z. Sun, Strengthening mechanism of aluminum on elastic properties of NbVTiZr highentropy alloys, Intermetallics. 92 (2018) 7-14. https://doi.org/10.1016/j.intermet.2017.09.003.

[18] A. R. Kheirandish, K. A. Nekouee, R. A. Khosroshahi, and N. Ehsani, Self-propagating high temperature synthesis of SiAlON, Int. J. Refract. Met. Hard Mater. 55 (2016) 68-79. https://doi.org/10.1016/j.ijrmhm.2015.11.010.

[19] H. Pourbagheri and H. Aghajani, SHS-Produced Al-Ti-B Master Alloys: Performance in Commercial Al Alloy, Int. J. Self-
Propagating High-Temperature Synth. 27 (2018) 245-254. https://doi.org/10.3103/S1061386218040052.

[20] S. A. Javadi, S. N. Hokmabadi, A. Taghizadeh, and H. Aghajani, Corrosion behavior , microstructure and phase formation of ternary $\mathrm{Ni}-\mathrm{Ti}-\mathrm{Si}$ nano composite synthesised by SHS method, Powder Metall. (2021) 1-10. https://doi.org/10.1080/00325899.2021.1906564.

[21] Q. Y. Hou, Microstructure and wear resistance of steel matrix composite coating reinforced by multiple ceramic particulates using SHS reaction of Al-TiO2-B2O3 system during plasma transferred arc overlay welding, Surf. Coatings Technol. 226 (2013) 113-122. https://doi.org/10.1016/j.surfcoat.2013.03.043.

[22] M. I. S. Argolo, L. S. Silva, J. M. Siqueira, F. da S. Miranda, M. E. Medeiros, and F. M. S. Garrido, Structural and optical properties of $\mathrm{Ni} / \mathrm{NiO}$ composites synthesized by eco-friendly self-propagation synthesis (SHS): Effects of NH4OH addition, Ceram. Int. 45 (2019) 21640-21646. https://doi.org/10.1016/j.ceramint.2019.07.161.

[23] X. Hou, J. Yu, and M. Sheng, Study on the preparation of the ceramic composite-lined steel pipe with the SHS reaction system of Al-Fe2O3-Cr2O3, Ceram. Int. 43 (2017) 11078-11082. https://doi.org/10.1016/j.ceramint.2017.05.153.

[24] X. Hou and J. Yu, Phase and structure formation mechanisms of SHS synthesized composite coatings, Ceram. Int. 44 (2018) 80128017. https://doi.org/10.1016/j.ceramint.2018.01.241.

[25] H. Li, X. Wang, L. Chai, H. Wang, Microstructure and mechanical properties of an in-situ TiB2/Al-Zn-Mg-Cu-Zr composite fabricated by Melt-SHS process, Mater. Sci. Eng. A. 720 (2018) 60-68. https://doi.org/10.1016/j.msea.2018.02.025.

[26] S. K. Mishra, S. K. Das, and V. Sherbacov, Fabrication of Al2O3$\mathrm{ZrB} 2$ in situ composite by SHS dynamic compaction: A novel approach, Compos. Sci. Technol. 67 (2007) 2447-2453. https://doi.org/10.1016/j.compscitech.2006.12.017.

[27] J. Xu, B. Zou, S. Tao, M. Zhang, and X. Cao, Fabrication and properties of $\mathrm{Al} 2 \mathrm{O} 3-\mathrm{TiB} 2-\mathrm{TiC} / \mathrm{Al}$ metal matrix composite coatings by atmospheric plasma spraying of SHS powders, J. Alloys Compd. 672 (2016) 251-259. https://doi.org/10.1016/j.jallcom.2016.02.116.

[28] P. Bazhin, A. Konstantinov, A. Chizhikov, A. Prokopets, and A. Bolotskaia, Structure, physical and mechanical properties of TiB-40 wt.\%Ti composite materials obtained by unrestricted SHS compression, Mater. Today Commun. 25 (2020) 101484. https://doi.org/10.1016/j.mtcomm.2020.101484.

[29] R. Trevino, E. Maguregui, F. Perez, and E. Shafirovich, Mechanically activated $\mathrm{SHS}$ of $\mathrm{Nb} 5 \mathrm{Si} 3$ and $\mathrm{Nb} 5 \mathrm{Si} 3 / \mathrm{Nb}$ composites, J. Alloys Compd. 826 (2020). https://doi.org/10.1016/j.jallcom.2020.154228.

[30] X. Fan, W. Huang, X. Zhou, and B. Zou, Preparation and characterization of NiAl-TiC-TiB2 intermetallic matrix composite coatings by atmospheric plasma spraying of SHS powders, Ceram. Int. 46 (2020) 10512-10520. https://doi.org/10.1016/j.ceramint.2020.01.052.

[31] S. K. Mishra, V. Gokuul, and S. Paswan, Alumina-titanium diboride in situ composite by self-propagating high-temperature synthesis (SHS) dynamic compaction: Effect of compaction pressure during synthesis, Int. J. Refract. Met. Hard Mater. 43 (2014) 19-24. https://doi.org/10.1016/j.ijrmhm.2013.10.018.

[32] Y. Liang, Z. Han, X. Li, Z. Zhang, and L. Ren, Study on the reaction mechanism of self-propagating high-temperature synthesis of TiC in the Cu-Ti-C system, Mater. Chem. Phys. 137 (2012) 200-206. https://doi.org/10.1016/j.matchemphys.2012.09.007

[33] Y. Li, S. Huang, P. Bai, B. Liu, and J. Wang, Effect of Ti/Si ratio on the products of laser igniting self-propagating high-temperature synthesis in Cu-Ti-Si system, J. Alloys Compd. 548 (2013) 245-248. https://doi.org/10.1016/j.jallcom.2012.08.078.

[34] A. S. M. International, ASM METALS HANDBOOK VOLUME 3 Alloy Phase Diagrams. (2008). 